\title{
Proposed Hybrid Power Optimization for Wind Turbine/Battery System
}

\author{
Saloua Belaid ${ }^{1}$, Djamila Rekioua $^{1 *}$, Adel Oubelaid $^{1}$, Djamel Ziane $^{1}$, Toufik Rekioua $^{1}$ \\ ${ }^{1}$ Laboratoire de Technologie Industrielle et de I'Information (LTII), Faculté de Technologie, Université de Bejaia, 06000 Bejaia, Algeria \\ * Corresponding author, e-mail: djamila.rekioua@univ-bejaia.dz
}

Received: 12 June 2021, Accepted: 16 August 2021, Published online: 29 November 2021

\begin{abstract}
This paper contributes to the feasibility of a wind turbine/battery system with a hybrid power optimization controller. The proposed method is based on a mathematical optimization approach and allows to achieve an efficient operation of the maximum power point tracking (MPPT) algorithms to obtain an optimal performance level of the wind system and a minimal stress on the battery storage. The different powers have been controlled by a power management control (PMC) method. The objectives of the PMC based are, in first part to satisfy the load power demand and in second part to maintain the state of charge of the battery bank to prevent blackout and to extend the batteries life. A measurement of wind speeds was made during a whole day using a data acquisition system at the laboratory. Also, the different wind turbine parameters were identified at the same Laboratory. All these parameters have been used in simulation models in order to obtain the most realistic mathematical models that are close to the experiment. Real time simulation is performed using RT LAB simulator and the obtained results were matching those obtained in numerical simulation using Matlab/ Simulink. The obtained results under two different wind speed profile, with the different comparisons are presented to show the feasibility and the improvement of the proposed study in terms of power, efficiency, time response and effect on battery state of charge under two different wind speeds profile.
\end{abstract}

Keywords

wind turbine, battery storage, hybrid maximum power point tracking, optimization, state of charge, power system

\section{Introduction}

Due to the different advantages of wind energy conversion systems (WECS) with battery storage, great attention has been accorded to them [1-7]. The most important advantage of these hybrid systems is not only to provide a continuous energy whatever the load variations and under different metrological conditions, but to generate the various sources in an intelligent way, by using power management controls (PMC), that satisfies the load demand and maintains the battery state of charge.

The main disadvantage of WECS is that the output power varies depending on the wind speeds. Therefore, it is not easy to keep the maximum wind turbine power output for all wind speed conditions. A variety of MPPT approaches have been considered. to track the maximum power point of the wind turbine [8-12]. They all have the objective of power maximization. However, each of them differs from the other according to different characteristics such as precision (accurate or no), tracking process, the need or not of microcontroller (nature of analog or digital circuits), difficulty of implementation with complex algorithms, convergence time (tracking factor), efficiency, price (more or less expensive), sensor number, independence or no of system characteristics, number of input variables, stability. The most used algorithms are Tip Speed Ratio (TSR), Hill Climbing Search (HCS), Optimal Torque Control (OTC), Power Signal Feedback (PSF), Fuzzy Logic Controller (FLC), Genetic Algorithm (GA), Artificial Neural Network (ANN) based controller; Adaptive Neuro-Fuzzy Inference System (ANFIS), Particle Swarm Optimization (PSO), ... . The HCS algorithm is the most popular approach because of its ease of implementation. It compares the previously delivered power with that after the disturbance. In the PSF method, a reference power signal is generated to obtain the optimal power $P_{\text {Tb-opt }}$. OTC method adjusts the generator torque to its optimal $T_{\text {em-opt }}$ at different wind speeds. In FLC, inputs controllers are power variation $\left(\Delta P_{T b}\right)$ and speed 
variation $\left(\Delta \omega_{T b}\right)$ and the output is the reference speed variation $\left(\Delta \omega_{T b, r e f}\right)$. In order to converge to the optimal point, the rules will depend on the variations of power and speed.

Different architectures of the multi-source system were suggested with different power management controls (PMC) Some of them are logic-based and others are intelligent-based. These are more interesting especially for stand-alone applications [13-24]. All PMC strategies are founded on the concept of output power control of each source and protecting the storage systems used. Authors in [13] synthesized the most important supervisory controls and different energy management methods used. In another study [14], an extensive review of energy management methods in renewable energy systems has been conducted. The authors in [15], have presented different methods to utilize excess energy in renewable systems. Different methods have been presented to improve the operation without additional cost. In [16], energy management control (EMC) is developed using a predictive control strategy and applied to a wind/photovoltaic system with battery storage. This method achieves optimal values and the overall cost has been reduced. In other studies [17, 18], Artificial intelligence methods are being extensively applied in supervision of renewable energy systems. For example, in [19-22], authors apply PMC for photovoltaic Installations and in [23, 24] for electric vehicle. The PMC developed in these publications, take into account all the input variables by considering the power optimization by a hybrid MPPT method. The supervision used allows controlling the different output powers, to protect the storage system and to regulate the $\mathrm{DC}$ voltage.

This paper discusses to the feasibility of a wind energy installation with a battery storage and equipped with a hybrid power optimization controller. This controller allows to achieve an efficient operation of the MPPT algorithms to obtain an optimal performance level of the wind system and a minimal stress on the battery of the studied system. This new and improved level of the controller is based on a mathematical optimization method. In this work, OTC and FLC methods have been first studied and then due to the advantages and disadvantages of each MPPT method, hybrid algorithm have been proposed ( $\mathrm{Hyb}(\mathrm{OTC} / \mathrm{FLC}))$.A PMC was also applied. It is based on control the different powers (the power supplied by the wind generator $\left(P_{T b}\right)$, the power supplied or required by the battery for compensation or recharge respectively $\left(P_{B a t}\right)$ and the power required by the load $\left(P_{\text {Load }}\right)$. The objectives of the PMC based are, in first part to satisfy the load power demand and in second part to maintain the state of charge of the battery bank to prevent blackout and to extend the batteries life. To keep constant the voltage DC bus constant whatever the wind speeds variations, field-oriented control (FOC) based on hysteresis current has been used.

The different wind turbine parameters were identified at the LTII Laboratory at the University of Bejaia (Algeria). Wind speeds measurements have been performed during a whole day using a data acquisition system (DAS). All these parameters have been used in simulation models in order to obtain the most realistic mathematical models that are close to the experiment. The obtained results using MATLAB/Simulink are presented and analyzed. The proposed PMC with hybrid MPPT algorithm (Hyb(OTC/FLC)) is integrated to the WECS with battery storage, under two wind speed profile. The first one reports experimental data from laboratory wind speed measurement system while the second one is based on data from a chosen step profile. The obtained results show a the best performances of $\mathrm{Hyb}(\mathrm{OTC} / \mathrm{FLC})$ in terms of power, response time, efficiency and effect on the battery state of charge level. Real time simulation is performed using RT LAB simulator in the LTII laboratory and the obtained results were matching to those obtained in simulation using Matlab/Simulink. The obtained results with the different comparisons are presented to show the feasibility and the improvement of the proposed study.

\section{System description}

The studied system configuration architecture is shown in Fig. 1. It comprises a wind turbine based on PMSG, A rectifier, DC/DC converter, batteries storage, a load and a power management control unit to manage the different powers. For the wind power maximization three hybrid algorithms have been proposed. The field-oriented control (FOC) has been used to keep the voltage DC bus constant whatever the wind speeds variations.

\section{Wind turbine parameters identification}

The installed wind turbine in the LTII Laboratory (Fig. 2) is about $900 \mathrm{~W}$ peak power with a Whisper controller and battery system.

The different identified parameters are listed in Table 1.

\section{Wind speed measurements}

Wind speed measurements from a data acquisition device were performed at the LTII laboratory (Fig. 3) at the university of Bejaia (Algeria). It is a coastal city in eastern 


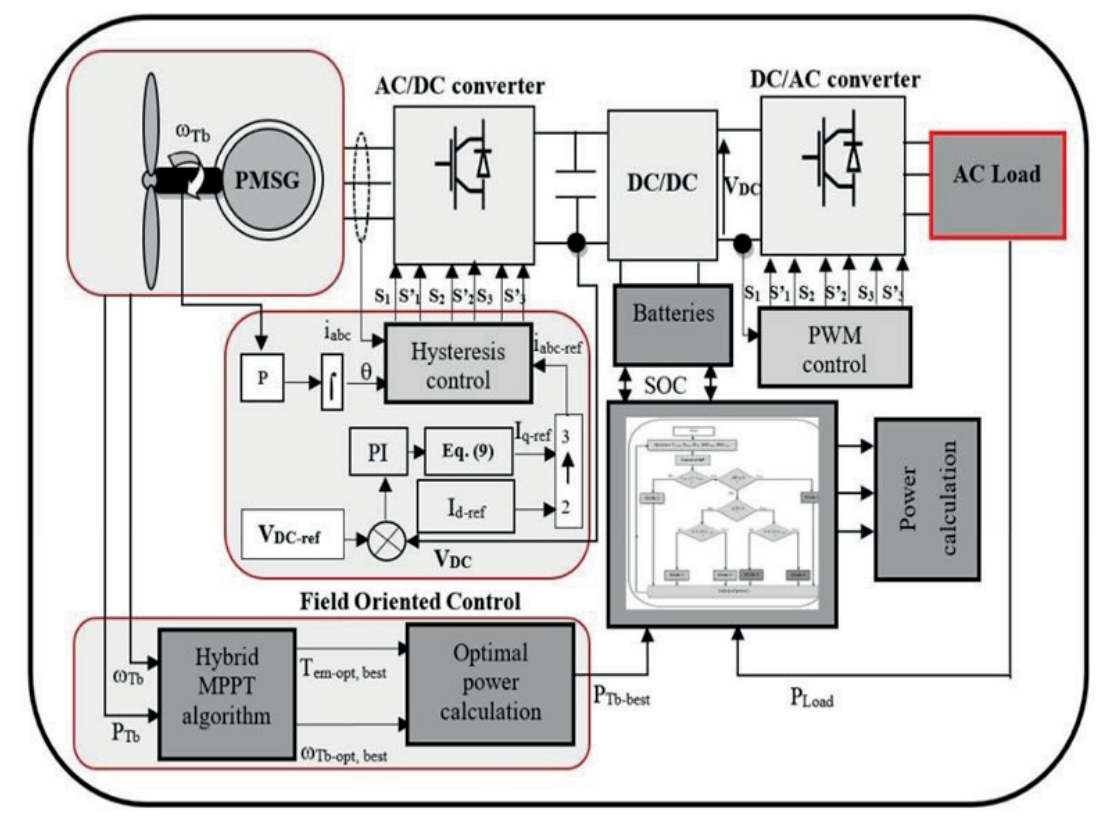

Fig. 1 Studied system

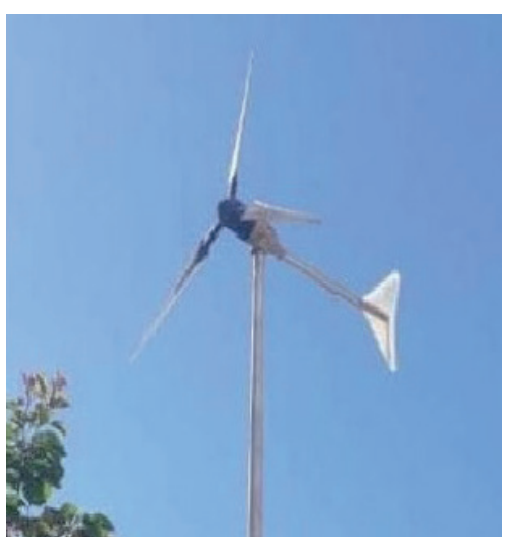

Fig. 2 Installed wind turbine

Table 1 Wind turbine parameters

\begin{tabular}{lc}
\hline Nominal power $P_{N}$ & $900 \mathrm{~W}$ \\
Resistance of the stator winding $\boldsymbol{R} s$ & $0.49 \Omega$ \\
Stator inductance $\boldsymbol{L} s$ & $0.0016 \mathrm{H}$ \\
Number of pole pairs $P$ & 5 \\
Flux $\Phi_{f}$ & $0.148 \mathrm{~Wb}$ \\
Turbine radius $\boldsymbol{R}_{T b}$ & $1.05 \mathrm{~m}$ \\
Total inertia $J$ & $0.016 \mathrm{~kg} / \mathrm{m}^{2}$ \\
Viscous friction coefficient $f$ & $0.0001 \mathrm{~N} \cdot \mathrm{m} \cdot \mathrm{s} \mathrm{rad}^{-1}$ \\
\hline
\end{tabular}

Algeria where the average wind speed potential reaches $6.8 \mathrm{~m} / \mathrm{s}$. The DAS consists of a sensor which allow to read the wind speeds $(\mathrm{m} / \mathrm{s})$, an inverter power interface box installed near the inverter and transmits information (wind speeds, voltage, current...) to the data interface as signals, a data interface recovers the signals from the

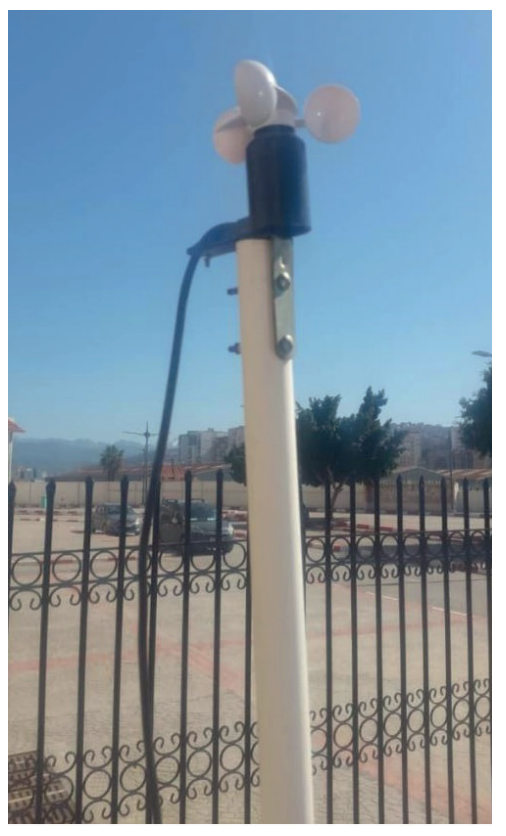

Fig. 3 Measurement system

various power interfaces to transmit them to the $\mathrm{PC}$ and a software for monitoring the different parameters and data (ACQUI-SOL). The software allows to display in real time, in the form of curves and numerical blocks, the different data (wind speed, voltage, current,...) and to display, after acquisition, the different curves. The sampling frequency during the acquisition of the data is chosen about $100 \mathrm{~ms}$ and the chosen acquisition period is 24 hours.

Fig. 4 shows the wind speeds during a whole day that will be used in the study. 


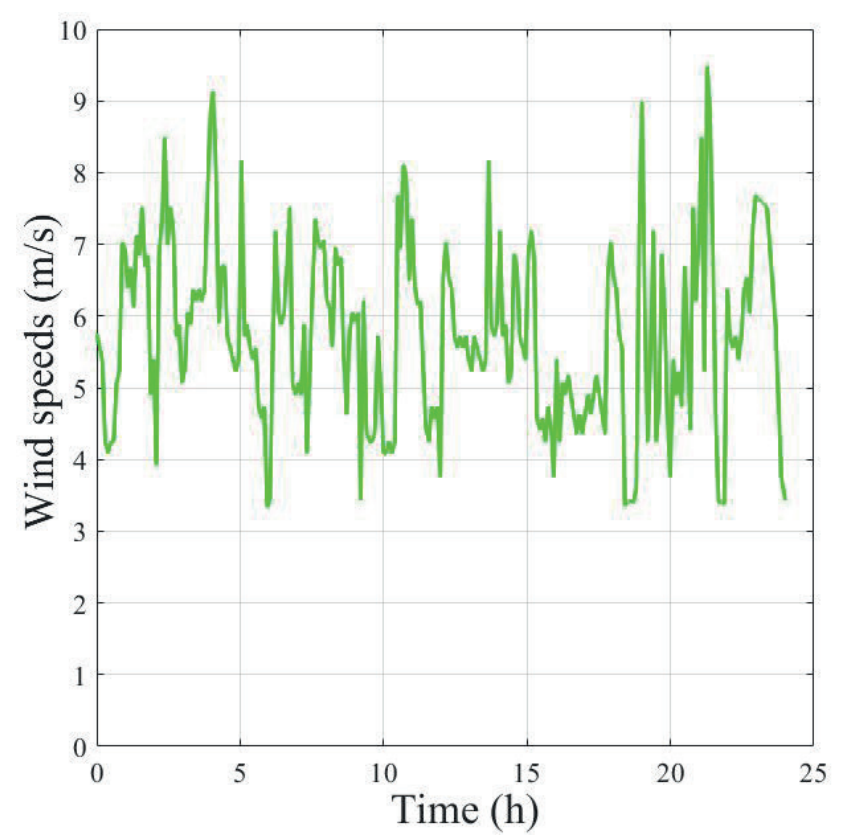

Fig. 4 Measured wind speeds profile at the site in January 2021

\section{Modeling of the proposed system}

\subsection{Wind turbine model}

The tip speed ratio (TSR) for wind turbines is defined as ratio between the rotational speed of the tip of a blade $\omega_{T b} \cdot R_{T b}$ and the actual wind speed $V_{\text {wind }}$ [25-27].

$\lambda=\omega_{T b} \cdot R_{T b} / V_{\text {Wind }}$

The mechanical power $P_{T b}$ is given by:

$P_{T b}=(1 / 2) \cdot C_{p} \cdot \rho \cdot \pi \cdot R_{T b}^{2} \cdot V_{\text {wind }}^{3}$.

The power coefficient $C_{p}$ has a unique maximum $C_{p \text {-opt }}$ that corresponds to a maximum power, where:

$\lambda_{\text {opt }}=\omega_{\text {Tb-opt }} \cdot R_{T b} / V_{\text {Wind }}$.

\subsection{PMSG model}

In $(d, q)$ reference frame, the electrical equations are [25]:

$V_{s d}=R_{s} I_{s d}+L_{d}\left(d I_{s d} / d t\right)-L_{q} \omega I_{s q}$

$V_{s q}=R_{s} I_{s q}+L_{q}\left(d I_{s q} / d t\right)+L_{d} \omega I_{s d}+\Phi_{f} \omega$,

$\omega=P \Omega$,

where $I_{s d}, I_{s q}, V_{s d}$ and $V_{s q}$ are respectively currents and voltages in the $(d, q)$ reference frame, $L_{d}$ and $L_{q}$ are the generator inductances in the $d$-q-axis, $P$ is the pole pair number, $R_{s}$ is the armature resistance, $\Phi_{f}$ is the permanent magnet flux and $\omega$ is the mechanical speed.

The mechanical equation is described as follows [27-29]:
$J .(d \Omega / d t)=T_{T b}-T_{e m}-f \Omega$,

$T_{e m}=(3 / 2)\left[\Phi_{f} \cdot I_{q}+\left(L_{d}-L_{q}\right) \cdot I_{d} \cdot I_{q}\right]$

$T_{e m}$ is the electromagnetic torque, $T_{T b}$ is the aerodynamic torque and $f$ is the the turbine rotor friction.

The field-oriented control (FOC) based on hysteresis current has been used to kept constant the voltage DC bus constant whatever the wind speeds variations.

$$
\begin{aligned}
& I_{\text {qref }}=\left(2 \cdot T_{\text {eref }}\right) /\left(3 \cdot \phi_{f} \cdot P\right) \\
& I_{\text {dref }}=0
\end{aligned}
$$

\subsection{Storage modeling}

This model it characterized by setting a series of electromotive force with a variable resistor, as shown in Fig. 5. For $n_{B a t}$ cells in series, the battery voltage can be written as $[24,30]$ :

$$
V_{\text {Bat }}=n_{\text {Bat }} \cdot E_{\text {Bat }} \pm n_{\text {Bat }} \cdot R_{\text {Bat }} \cdot I_{\text {Bat }} \text {, }
$$

where: $V_{B a t}$ terminal battery voltage, $E_{B a t}$ open circuit voltage, $R_{B a t}$ battery internal resistance, $I_{B a t}$ battery current and $n_{B a t}$ series cells.

The capacity model, giving the amount of energy is given by Eq. (13). It is based on the current $I_{10}$, which corresponds to the operating speed at $C_{10}$, while $T$ is the heating of the accumulator at an ambient temperature [24, 29, 30].

$\mathrm{C}_{\text {Bat }}=\mathrm{C}_{10 .}\left(1.67 /\left(1+0.67\left(\mathrm{I} / \mathrm{I}_{10}\right)\right)\right) \cdot(1+0.005 . \Delta \mathrm{T})$

The state of battery charge is:

$S O C=1-\frac{Q}{C_{B a t}}$,

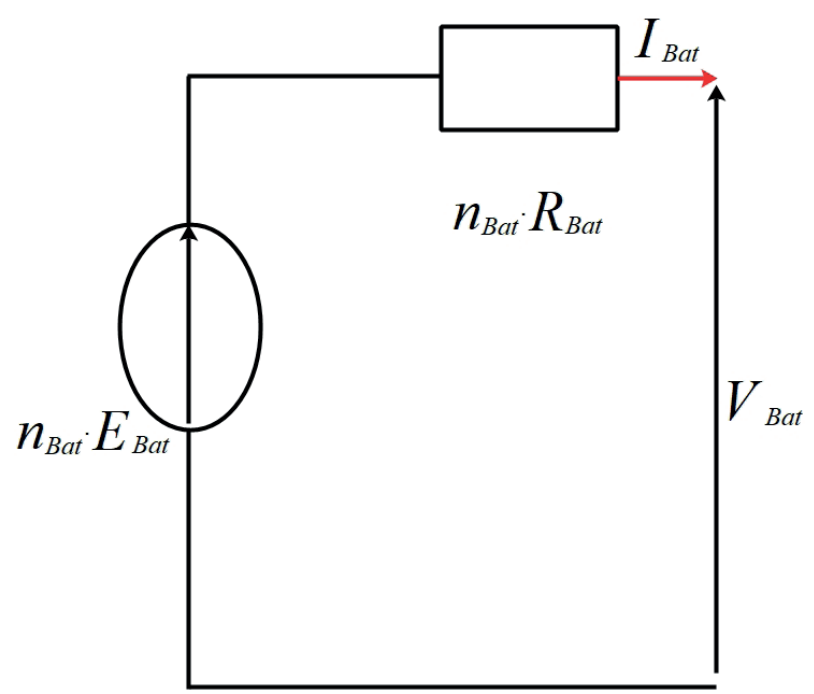

Fig. 5 Battery equivalent circuit model 
with:

$Q=I_{\text {Bat }} . t$,

where $t$ is the discharging time.

The voltage battery in charging mode is given as [24]:

$V_{\text {Bat }-c h}=n_{\text {Bat }}[2+0.16 S O C]+n_{\text {Bat }}\left(I_{\text {Bat }} / C_{10}\right)$

$\left[6 /\left(1+I_{\text {Bat }}^{1.3}\right)+\left(0.27 /\right.\right.$ SOC $\left.\left.^{1.5}\right)+0.002\right](1-0.007(T-25))$,

and in discharging mode, it is given as:

$$
\begin{aligned}
& V_{\text {Bat -dis }}=n_{\text {Bat }}[1.965+0.12 S O C]-n_{\text {Bat }}\left(I_{\text {Bat }} / C_{10}\right) \\
& {\left[4 /\left(1+I_{\text {Bat }}^{1.3}\right)+\left(0.27 / \text { SOC }^{1.5}\right)+0.002\right](1-0.007(T-25)) .}
\end{aligned}
$$

\section{Maximum power point tracking (MPPT) algorithms}

In our work, two methods (OTC and FLC). have been chosen to combine them. It is obtained a hybrid method which is the combination of the two methods. This optimization method is proposed to obtain better performances.

The first step allows us to choose the different optimal values of each MPPT algorithm. Then the second step gives the chosen best values of rotational speed and electromagnetic torque. Finally, in the third step, the selected best optimized turbine power is obtained. The proposed optimized power calculation can be represented in the following flowchart (Fig. 6).

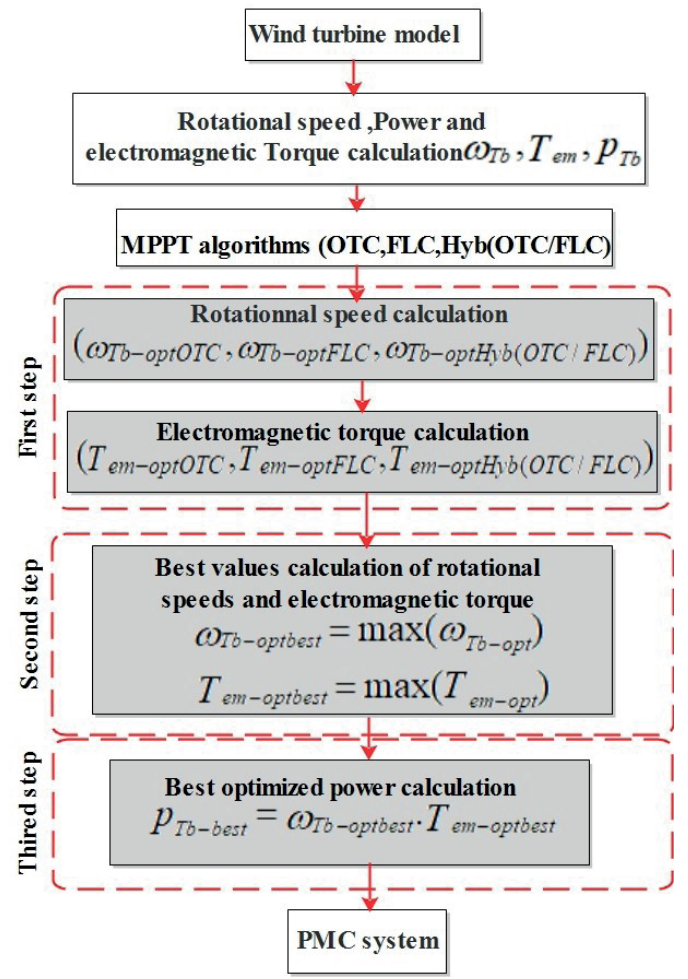

Fig. 6 Proposed power optimization calculation
With: $\omega_{\text {optOTC }}, \omega_{\text {optFLC }}, \omega_{\text {optHyb(OTCFLC) }}$ are the different rotational speed values of each MPPT method, $T_{\text {em-optOTC }}$, $T_{\text {em-optFLC }}, T_{\text {em-optHyb(OTCFLC) }}$ are different electromagnetic torque values of each MPPT method, $P_{\text {Tb-best }}$ is the selected best optimized turbine power, $\omega_{T b \text {-opt }}$ is the optimal turbine rotational speed, $\omega_{T b \text {-opt,best }}$ is the selected best optimal turbine rotational speed, $T_{\text {em-opt,best }}$ is the selected best optimal electromagnetic torque and $T_{\text {em-opt }}$ is the optimal electromagnetic torque.

\section{Simulation results with the different MPPT algorithms}

The simulations are performed using Matlab/Simulink taking into account the measured wind speed profile of Fig. 4. which represents wind speeds variation of a whole day. Figs. 7 and 8 represent, respectively, the mechanical power and electromagnetic torque using the three MPPTs used for the wind turbine and simulated under the same wind speed profile. It can be noticed that hybrid MPPT method ( $\mathrm{Hyb}(\mathrm{OTC} / \mathrm{FLC}))$ gives the best results in terms of power and electromagnetic torque.

Voltage battery is represented in Fig. 9 and the state of charge in Fig. 10. It is observed that the battery voltage remains around its reference voltage of $24 \mathrm{~V}$ for the hybrid method. The less stress on the battery when using the simple MPPT methods will lead to a reduction in battery discharge. In Fig. 10 it is also noticed at startup (Zoom1), the $\mathrm{Hyb}(\mathrm{OTC} / \mathrm{FLC})$ method does not stress the battery much and their SOC stays around the $\mathrm{SOC}_{\max }$ of $90 \%$, contrary to the FLC method which brings the SOC down to $78.59 \%$ and in the OTC method the SOC increases to $76.68 \%$.

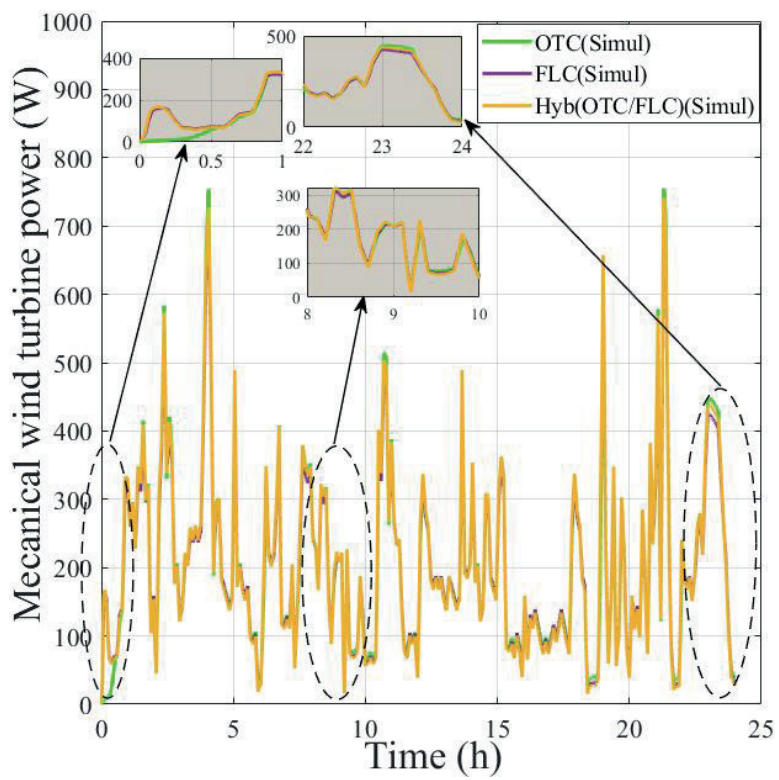

Fig. 7 Mechanical power 


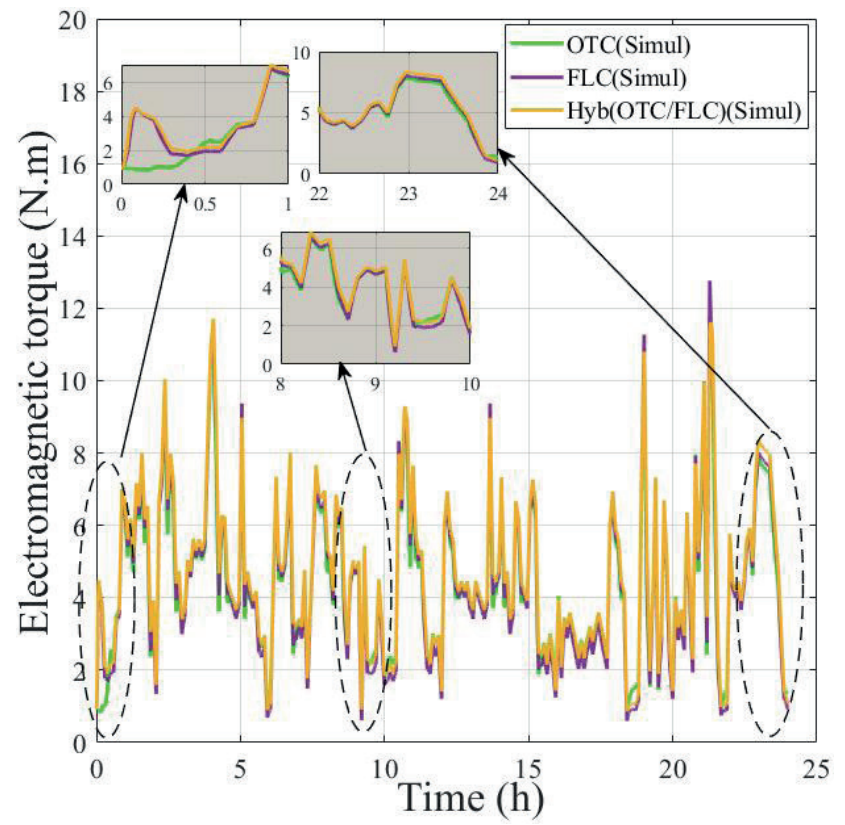

Fig. 8 Electromagnetic torque

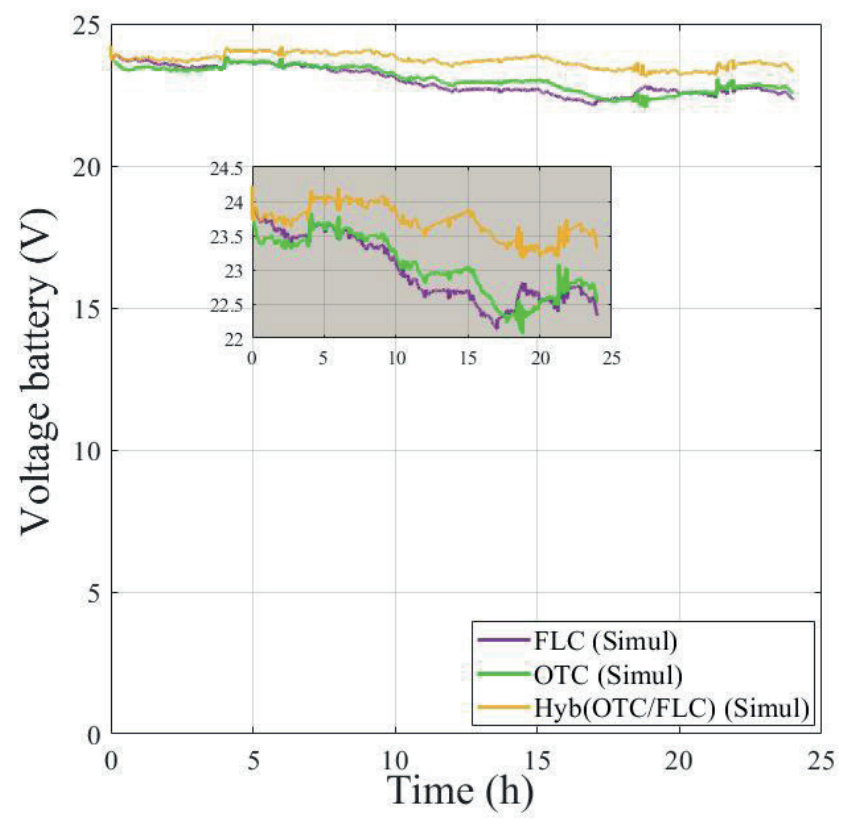

Fig. 9 Voltage battery

It is also shown that the $\mathrm{SOC}_{\text {min }}$ with the hybrid MPPT is around $60 \%$ unlike OTC and FLC MPPT method where the $\mathrm{SOC}_{\text {min }}$ brings to $30 \%$. To conclude, the simulation results reveal that the proposed hybrid method provides better results than the standard non-hybrid methods. It is also observed that when using hybrid method, the SOC remains around a maximum value of $90 \%$ unlike the two other methods (OTC and FLC).

In order to compare the different methods in terms of efficiency, power and effect on the state of charge of the battery, a step change wind speed profile was chosen (Fig. 11).

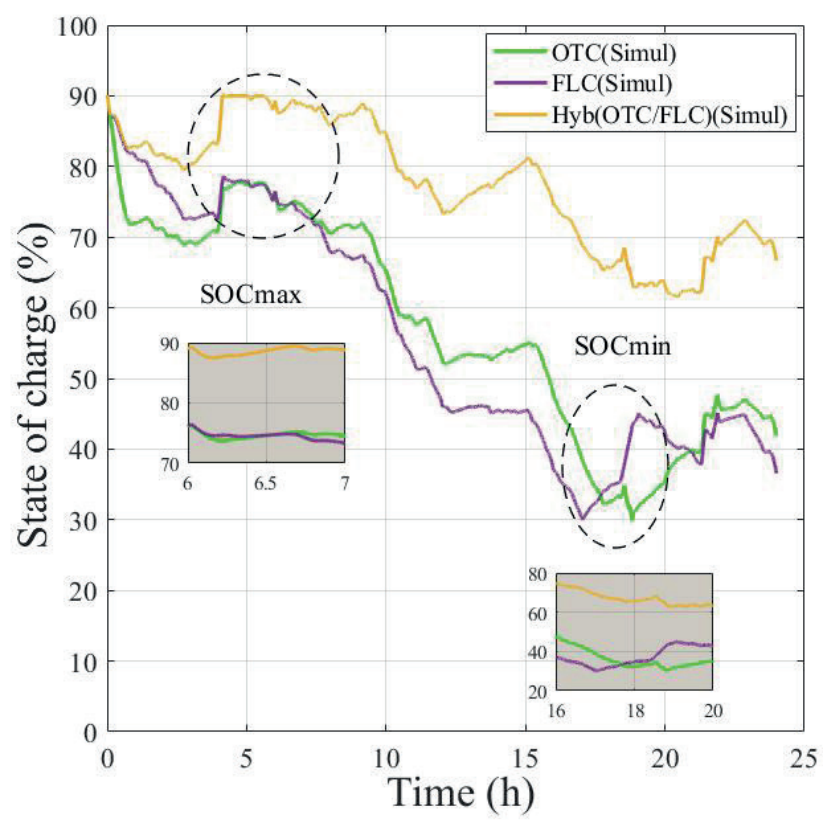

Fig. 10 Battery state of charge

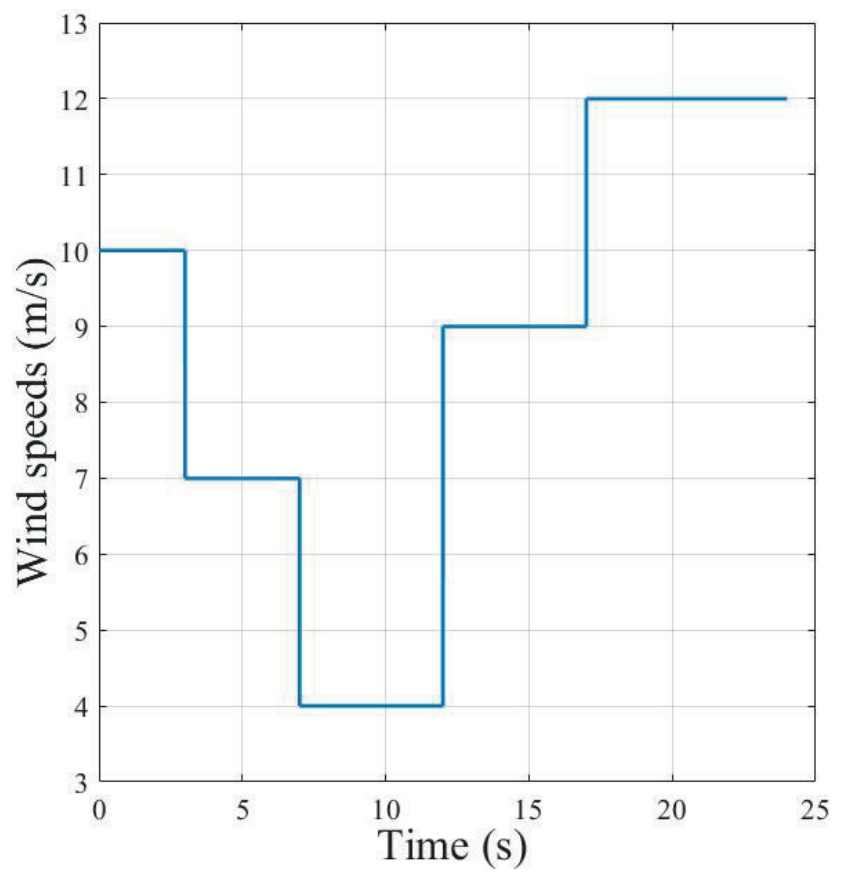

Fig. 11 Step wind speed profile

The turbine power waveform using the different MPPT methods is shown in Fig. 12. In order to calculate the different power for each MPPT method, different zooms were taken for each time interval which represents a given constant speed.

The different power values are reported in Table 2.

It is noticed that the $\mathrm{Hyb}(\mathrm{OTC} / \mathrm{FLC})$ method gives the highest power values for all wind speeds (from 4 to $12 \mathrm{~m} / \mathrm{s}$ ). The efficiency of each method has been calculated and summarized in Table 3. 


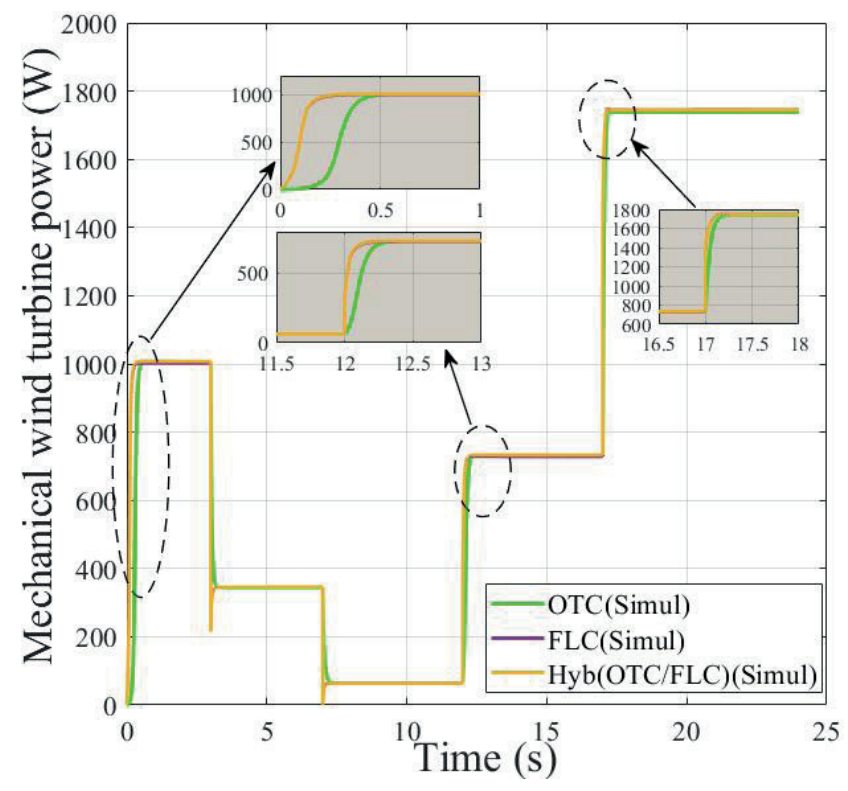

Fig. 12 Mechanical power

It is very obvious from the previous result of the powers that for any wind speed, the Hyb(OTC/FLC) method will give the best efficiency. As for the response time, a comparison of the different methods is summarized in Table 4.

Table 2 Evaluation of the different powers

\begin{tabular}{lcccc}
\hline$V_{\text {wind }}(\mathrm{m} / \mathrm{s})$ & Without MPPT & OTC & FLC & Hyb(OTC/FLC) \\
\hline 10 & 888.10 & 1005.00 & 1002.00 & 1008.00 \\
7 & 303.80 & 343.60 & 345.40 & 345.30 \\
4 & 56.29 & 63.58 & 63.68 & 63.76 \\
9 & 647.00 & 732.00 & 728.60 & 732.90 \\
12 & 1536.00 & 1539.31 & 1746.00 & 1745.00 \\
\hline
\end{tabular}

Table 3 MPPT Efficiency of each control strategy

\begin{tabular}{lllc}
\hline$V_{\text {wind }}(\mathrm{m} / \mathrm{s})$ & \multicolumn{3}{c}{$\eta_{M P P T}(\%)$} \\
\hline 10 & OTC & FLC & Hyb(OTC/FLC $)$ \\
7 & 98.42 & 98.13 & 98.72 \\
4 & 98.10 & 98.62 & 98.59 \\
9 & 97.29 & 97.44 & 97.57 \\
12 & 98.34 & 97.88 & 98.46 \\
\hline
\end{tabular}

Table 4 Comparison of the different methods in terms of response time

\begin{tabular}{lcccc}
\hline \multirow{2}{*}{$V_{\text {wind }}(\mathrm{m} / \mathrm{s})$} & Without MPPT & OTC & FLC & Hyb(OTC/FLC $)$ \\
\hline 10 & 5.710 & 0.632 & 0.383 & 0.365 \\
7 & 0.297 & 0.209 & 0.220 & 0.270 \\
4 & 0.808 & 0.781 & 0.301 & 0.378 \\
9 & 0.038 & 0.052 & 0.031 & 0.035 \\
12 & 0.024 & 0.033 & 0.022 & 0.020 \\
\hline
\end{tabular}

It is clear that the hybrid MPPT method responds faster than the non-hybrid methods whatever the wind speeds in terms of state of charge (Fig. 13). It can be seen that at startup, the $\mathrm{Hyb}(\mathrm{OTC} / \mathrm{FLC})$ method keeps its state of charge between a $\mathrm{SOC}_{\max }$ of $90 \%$ and a $\mathrm{SOC}_{\min }$ of $50 \%$. When using non hybrid methods, battery SOC reaches a $\mathrm{SOC}_{\min }$ of $40 \%$.

Hence, one can conclude that the hybridization resulted in saving around $10 \%$ of battery state of charge. All proposed methods were effective in recovering the maximum amount of wind power and were able to achieve the optimal power coefficient at all times.

The different SOC values during the different time intervals have been reported in Table 5 .

The proposed hybrid method is more efficient than the other non-hybrid methods in terms of power, electromagnetic torque, speed and efficiency. In addition, to that, it has enabled the reduction stress applied on storage batteries. It can be deduced that Hyb(OTC/FLC) method offers often the best performances, so this method will be used in our work.

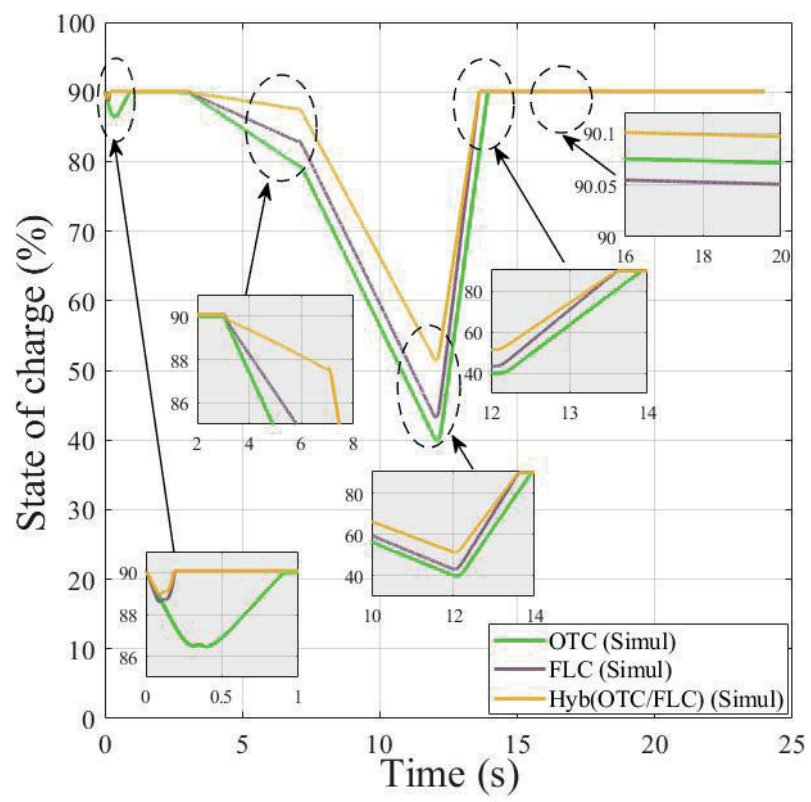

Fig. 13 State of charge under chosen step profile

Table 5 Different values of SOC of the different studied methods

\begin{tabular}{lccc}
\hline$V_{\text {wind }}(\mathrm{m} / \mathrm{s})$ & \multicolumn{3}{c}{ SOC $(\%)$} \\
\hline 10 & OTC & FLC & Hyb(OTC/FLC) \\
\hline 7 & 90.04 & 90.07 & 90,04 \\
4 & 79.50 & 82.88 & 84.72 \\
9 & 40.00 & 43.35 & 48.55 \\
12 & 90.01 & 90.06 & 90.08 \\
\hline
\end{tabular}




\section{Real time simulation using Rt Lab simulator}

The proposed soft transition strategy was executed in real time using OPAL RT LAB simulator. Fig. 14. shows the real time simulation bench established in our research laboratory which contains the host PC, the FPGA based real time simulator (OP 5700), a unit measurement, a data acquisition interface (OP8660) and an oscilloscope. After the simulation system was decomposed and adapted for use in RT LAB, a real time simulation was conducted. The measured wind speeds profile (Fig. 4) has been applied. The obtained results are compared to the simulation ones (Figs. 15-18). In Figs. 15 and 16, three zooms have been

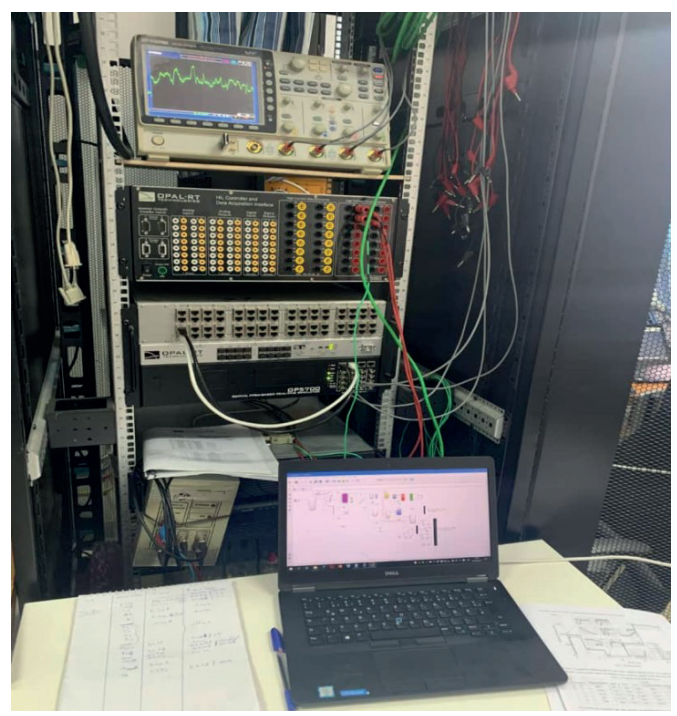

Fig. 14 Test bench

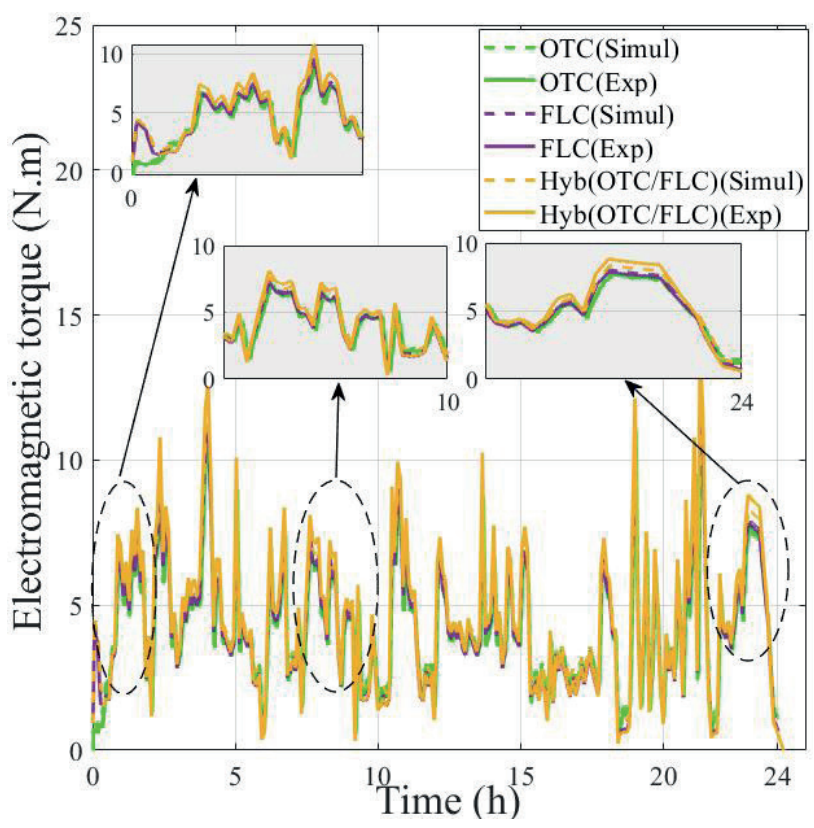

Fig. 15 Simulation and experimental waveforms of electromagnetic torque under measured wind profile

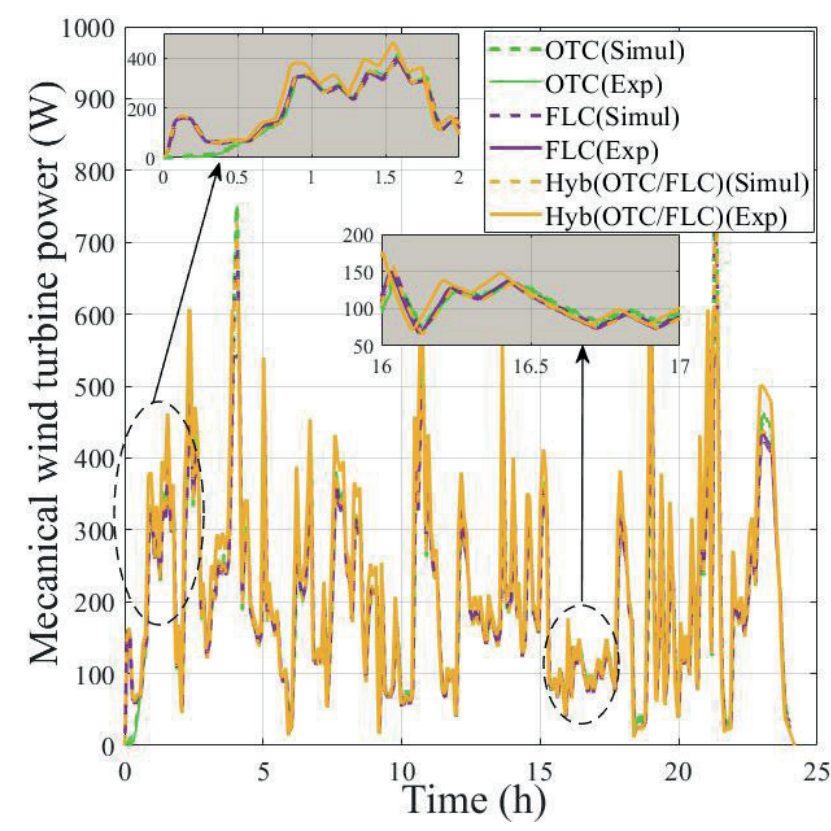

Fig. 16 Simulation and experimental waveforms of mechanical powers under measured wind profile

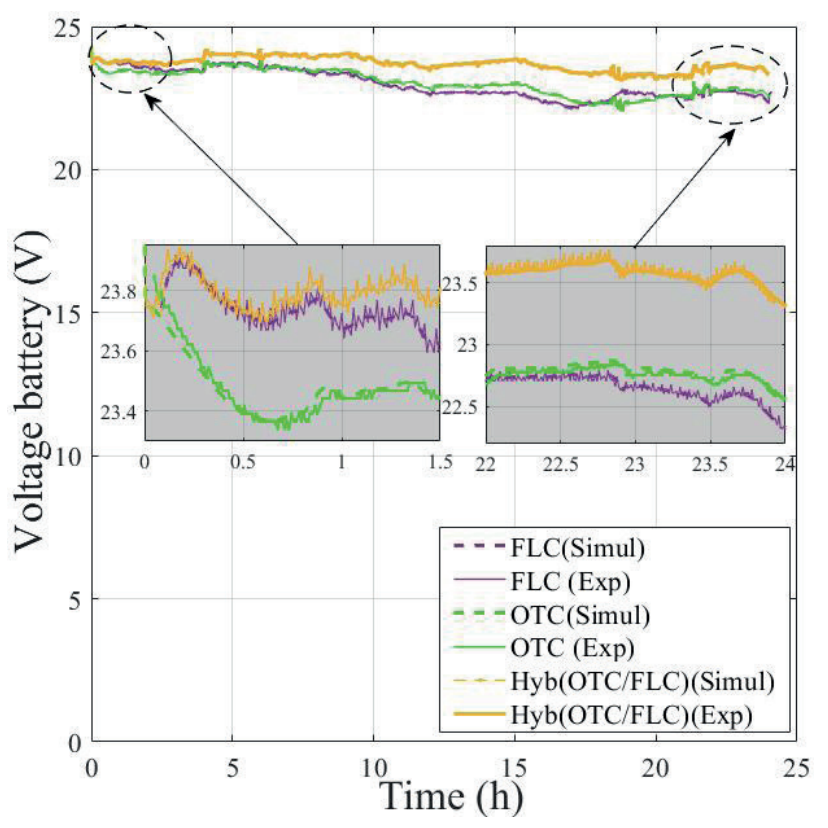

Fig. 17 Simulation and experimental waveforms of battery voltage under measured wind profile

made on the electromagnetic torque and mechanical power waveforms under the measured wind profile. It should be observed that the simulation results are also very close to the experimental ones with the same remarks previously mentioned in simulation results.

The hybrid method (OTC/FLC) provides the best performances, particularly for the battery voltage (Fig. 17) which keeps almost constant and for the SOC values (Fig. 18) given by the hybrid method (OTC/FLC). 
And in order to make comparisons between the simulation and the experimental results of the three methods in terms of efficiency, power and effect on the battery state of charge, the same step wind speeds profile (Fig. 11) is taken. The different results are listed (Figs. 19-22).

It can be seen that the simulation results are very close to the experimental ones, especially for the battery voltage (Fig. 22) which remains almost constant provided by the hybrid method (OTC/FLC). Under two different wind speed profiles, the simulation results are very similar to the experimental ones, which confirms the used model.

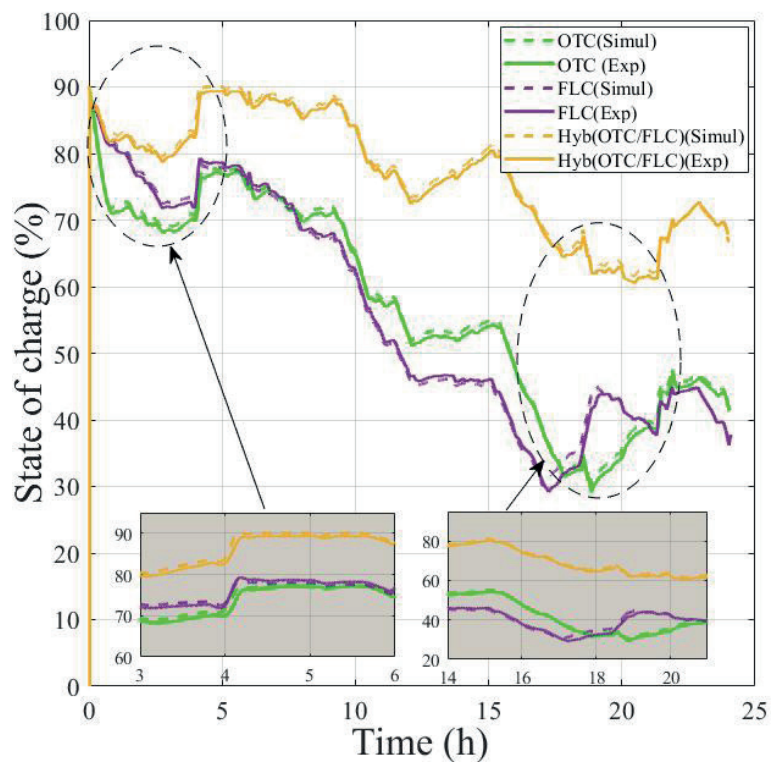

Fig. 18 Simulation and experimental waveforms of battery state of charge under measured wind profile

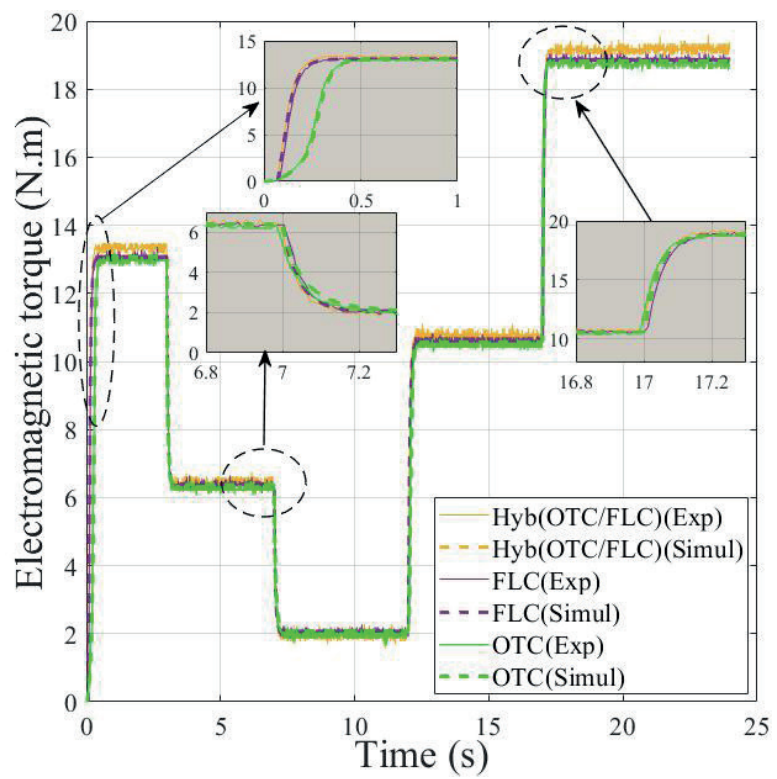

Fig. 19 Simulation and experimental waveforms of electromagnetic torque under step wind profile

\section{Application to hybrid wind turbine/batteries system}

An application has been made using the $\mathrm{Hyb}(\mathrm{OTC} / \mathrm{FLC})$ MPPT in wind turbine/batteries system with PMC. It is based on a system of switches. Where the switch $K_{4}$ is used for the main source (Wind energy), the switch $K_{1}$ is used for battery and the switch $K_{3}$ for the compensation of the two sources. While the switch $K_{2}$ is used for the excess power (Fig. 23).

The available power is expressed as follows:

$\Delta P=P_{T b}-P_{\text {Load }}$.

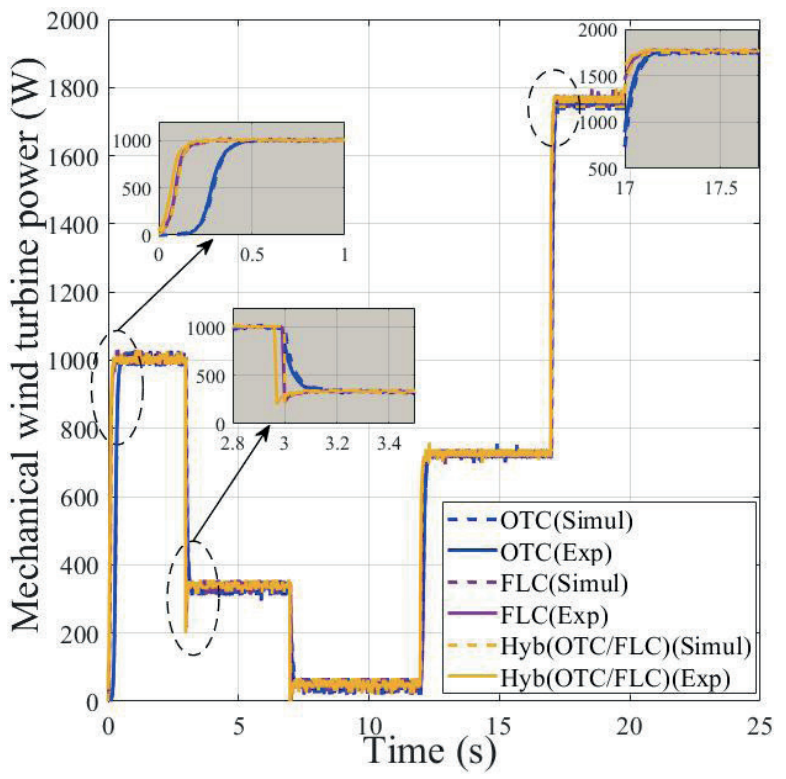

Fig. 20 Simulation and experimental waveforms of mechanical powers under step wind profile

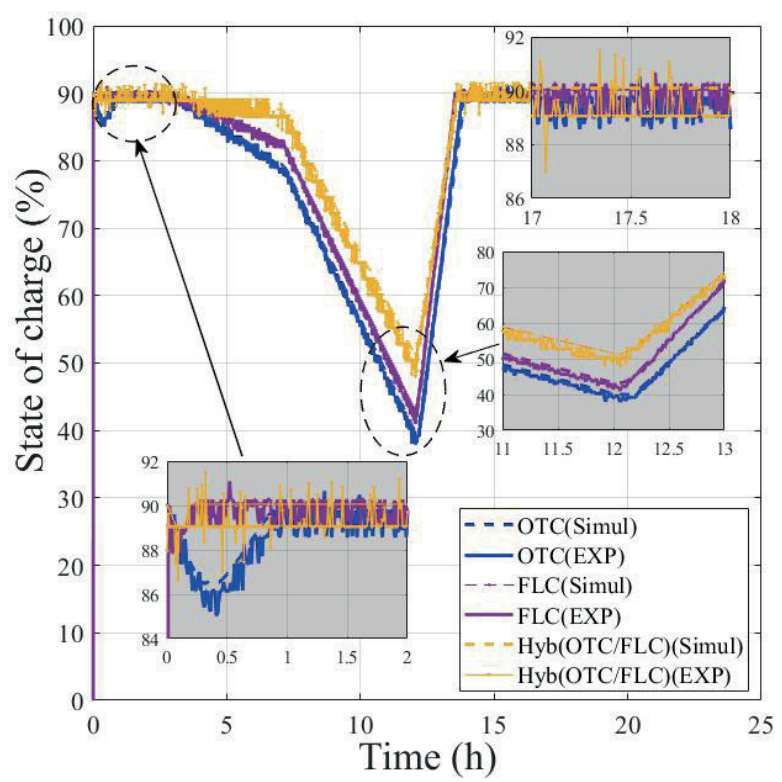

Fig. 21 Simulation and experimental waveforms of battery state of charge under step wind profile 


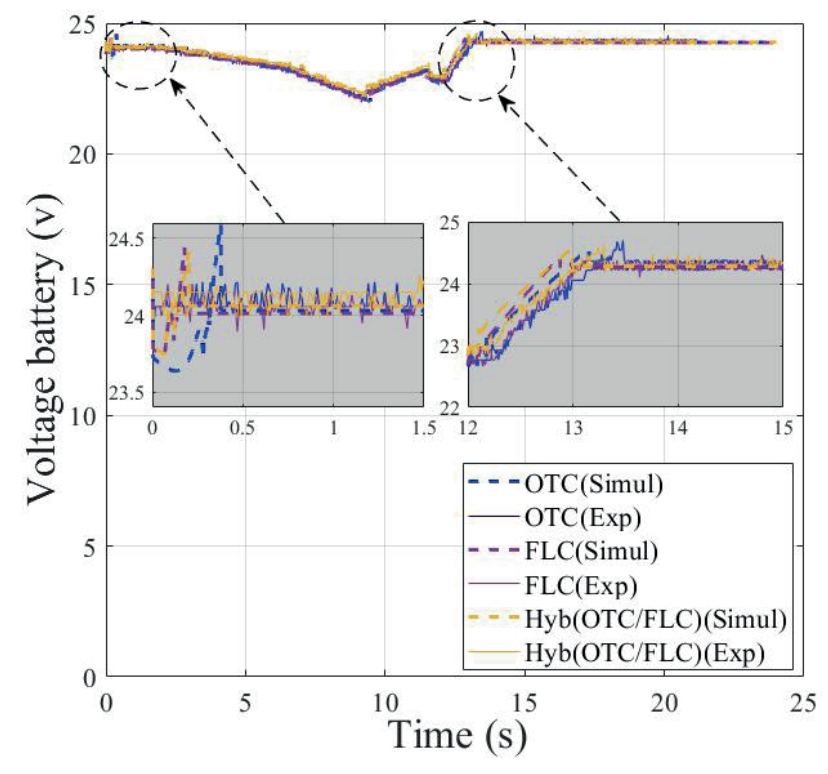

Fig. 22 Simulation and experimental waveforms of battery voltage under step wind profile

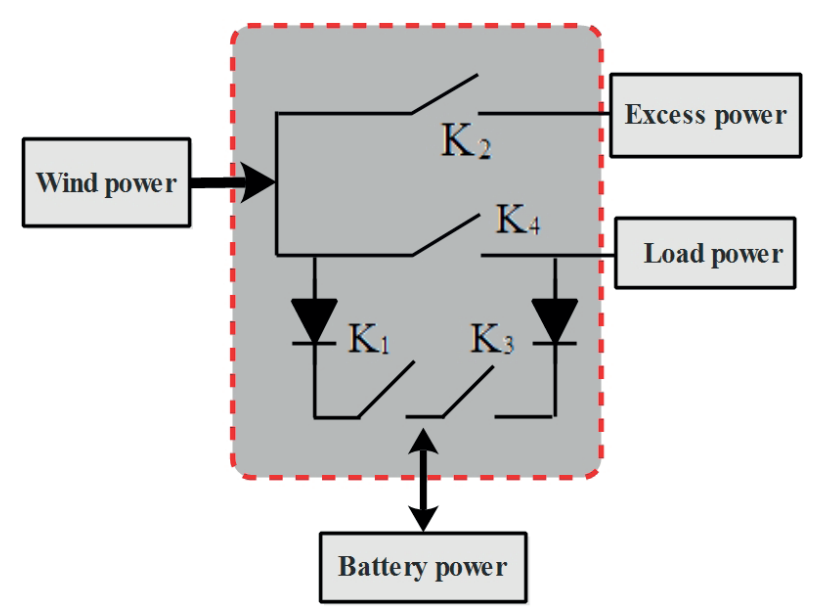

Fig. 23 Proposed Power management control

It is represented in Fig. 24 and the different powers are plotted in Fig. 25 It can be noticed that the proposed PMC has well-managed the different sources. Also, a good sizing was done that is a reason that the batteries have not been requested too much. Moreover, with the proposed $\mathrm{Hyb}(\mathrm{OTC} / \mathrm{FLC})$, there has been an increase in wind turbine power, so less stress on the batteries.

\section{Conclusion}

In this paper, the optimization of a wind turbine/battery system has been presented. This approach is proposed to obtain an efficient operation of the MPPT algorithms. This allows us to obtain an optimal level of the wind system

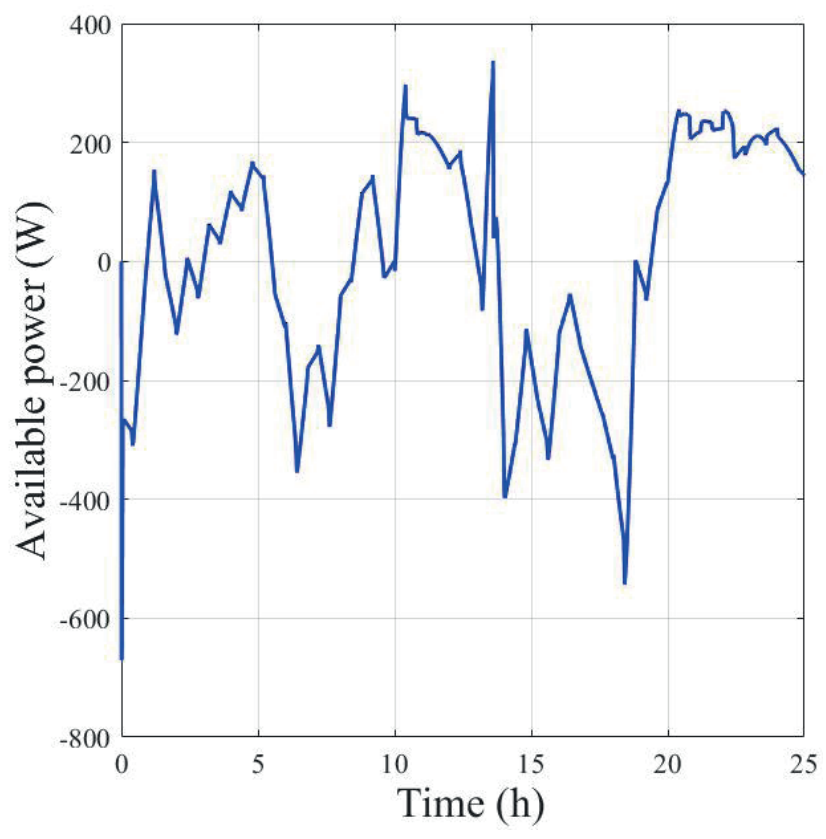

Fig. 24 Available power

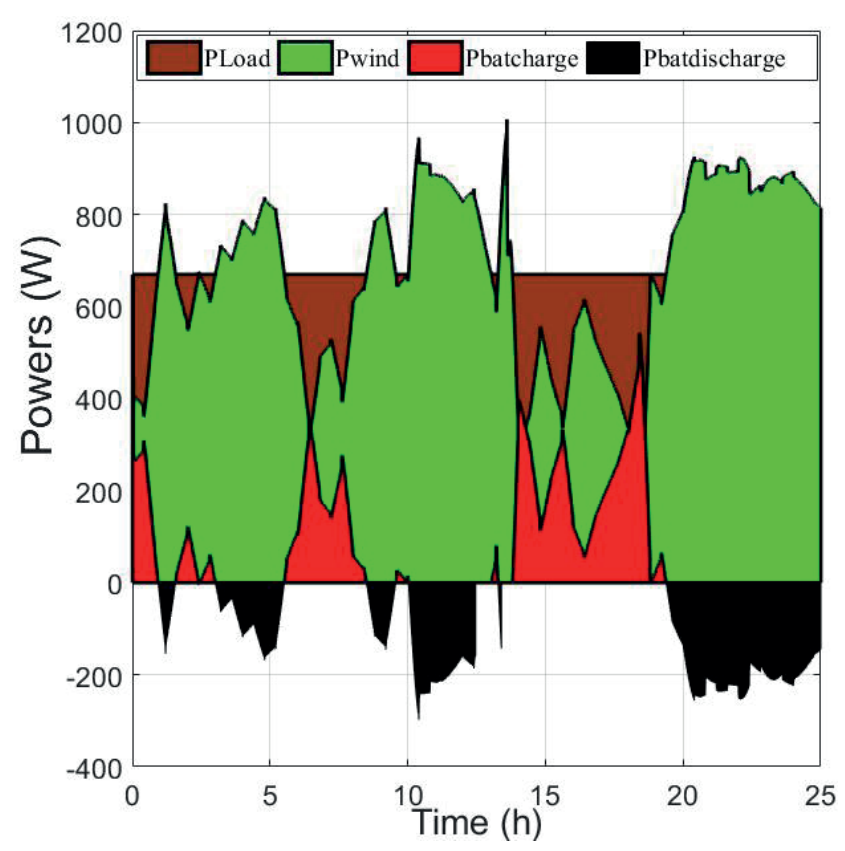

Fig. 25 The obtained different powers waveforms

performances and a minimal stress on the storage battery. Then, it was applied in a wind turbine /battery system with power management control. The developed power control reaches the fixed objectives and the obtained results clearly show the good operation of the hybrid system whatever the weather conditions variations. Real-time simulations performed with the RT LAB simulator have confirmed the effectiveness of the proposed method. 


\section{References}

[1] Manwell, J. F., Mc Gowan, J. G., Rogers, A. L. "Wind Energy Explained: Theory, Design and Application", John Wiley and Sons Ltd., Hoboken, NJ, USA, 2009. https://doi.org/10.1002/9781119994367

[2] Mazouz, L., Zidi, S. A., Hafaifa, A., Hadjeri, S., Benaissa, T. "Optimal Regulators Conception for Wind Turbine PMSG Generator Using Hooke Jeeves Method", Periodica Polytechnica Electrical Engineering and Computer Science, 63(3), pp. 151-158, 2019. https://doi.org/10.3311/PPee.13548

[3] Saidi, Y., Mezouar, A., Miloud, Y., Brahmi, B., Kerrouche, K. D. E., Benmahdjoub, M. A. "Adaptive Maximum Power Control Based on Optimum Torque Method for Wind Turbine by Using Fuzzy-Logic Adaption Mechanisms during Partial Load Operation", Periodica Polytechnica Electrical Engineering and Computer Science, 64(2), pp. 170-178, 2020.

https://doi.org/10.3311/PPee.15155

[4] Idjdarene, K., Rekioua, D., Rekioua, T., Tounzi, A. "Wind energy conversion system associated to a flywheel energy storage system", Analog Integrated Circuits and Signal Processing, 69(1), pp. 67-73, 2011.

https://doi.org/10.1007/s10470-011-9629-2

[5] Yaichi, I., Semmah, A., Wira, P. "Control of Doubly Fed Induction Generator with Maximum Power Point Tracking for Variable Speed Wind Energy Conversion Systems", Periodica Polytechnica Electrical Engineering and Computer Science, 64(1), pp. 87-96, 2020.

https://doi.org/10.3311/PPee.14166

[6] Amrouche, S. O., Rekioua, D., Rekioua, T. "Overview of energy storage in renewable energy systems", In: 2015 IEEE 3rd International Renewable and Sustainable Energy Conference, (IRSEC), Marrakesh, Morocco, 2016, pp. 1-6. https://doi.org/10.1109/IRSEC.2015.7454988

[7] Gubański, A., Sobkowiak, A., Jasiński, M., Kaczorowska, D., Janik, P., Kostyła, P., Leonowicz, Z., Rezmer, J., Sikorski, T., Suresh, V. "Hybrid Power Plant with Storage System: University Research Station", Periodica Polytechnica Electrical Engineering and Computer Science, 64(1), pp. 47-52, 2020.

https://doi.org/10.3311/PPee.14587

[8] Kumar, D., Chatterjee, K. "A review of conventional and advanced MPPT algorithms for wind energy systems", Renewable and Sustainable Energy Reviews, 55, pp. 957-970. 2016. https://doi.org/10.1016/j.rser.2015.11.013

[9] Abo-Khalil, A. G., Alghamdi, A. S. "MPPT of Permanent Magnet Synchronous Generator in Tidal Energy Systems Using Support Vector Regression", Sustainability, 13(4), Article number: 2223, 2021. https://doi.org/10.3390/su13042223

[10] Cui, Z., Song, L., Li, S. "Maximum Power Point Tracking Strategy for a New Wind Power System and Its Design Details", IEEE Transactions on Energy Conversion, 32(3), pp. 1063-1071. 2017. https://doi.org/10.1109/TEC.2017.2694008

[11] Dalala, Z. M., Zahid, Z. U., Yu, W., Cho, Y., Lai, J.-S. "Design and Analysis of an MPPT Technique for Small-Scale Wind Energy Conversion Systems", IEEE Transactions on Energy Conversion, 28(3), pp. 756-767. 2013.

https://doi.org/10.1109/TEC.2013.2259627
[12] Achour, A., Rekioua, D., Mohammedi, A., Mokrani, Z., Rekioua, T., Bacha, S. "Application of Direct Torque Control to a Photovoltaic Pumping System with Sliding-Mode Control Optimization", Electric Power Components and Systems, 44(2), pp.172-184, 2016. https://doi.org/10.1080/15325008.2015.1102182

[13] Rekioua, D. "Energy Management for PV Installations", In:Yahyaoui, I. (ed.) Advances in Renewable Energies and Power Technologies, Volume 1., Elsevier Science, Amsterdam, Netherlands, 2018, pp. 349-369.

https://doi.org/10.1016/B978-0-12-812959-3.00011-3

[14] Abedi, S., Alimardani, A., Gharehpetian, G. B., Riahy, G. H., Hosseinian, S. H. "A comprehensive method for optimal power management and design of hybrid RES-based autonomous energy systems", Renewable and Sustainable Energy Reviews, 16(3), pp. 1577-1587, 2012.

https://doi.org/10.1016/j.rser.2011.11.030

[15] Ismail, M. S., Moghavvemi, M., Mahlia, T. M. I., Muttaqi, K. M., Moghavvemi, S. "Effective utilization of excess energy in standalone hybrid renewable energy systems for improving comfort ability and reducing cost of energy: A review and analysis", Renewable and Sustainable Energy Reviews, 42, pp. 726-734, 2015.

https://doi.org/10.1016/j.rser.2014.10.051

[16] Robyns, B., Davigny, A., Saudemont, C. "Methodologies for supervision of Hybrid Energy Sources based on Storage Systems - A survey", Mathematics and Computers in Simulation, 91, pp. 52-71, 2013.

https://doi.org/10.1016/j.matcom.2012.06.014

[17] Farhadi, M., Mohammed, O. "Adaptive Energy Management in Redundant Hybrid DC Micro Grid for Pulse Load Mitigation", IEEE Transactions on Smart Grid, 6(1), pp. 54-62, 2015. https://doi.org/10.1109/TSG.2014.2347253

[18] Hosseinzadeh, M., Salmasi, F. R. "Power management of an isolated hybrid AC/DC micro-grid with fuzzy control of battery banks", IET Renewable Power Generation, 9(5), pp. 484-493, 2015. https://doi.org/10.1049/iet-rpg.2014.0271

[19] Hassani, H., Zaouche, F., Rekioua, D., Belaid, S., Rekioua, T., Bacha, S. "Feasibility of a standalone photovoltaic/battery system with hydrogen production", Journal of Energy Storage, 31, Article number: 101644, 2020.

https://doi.org/10.1016/j.est.2020.101644

[20] Serir, C., Rekioua, D., Mezzai, N., Bacha, S. "Supervisor control and optimization of multi-sources pumping system with battery storage", International Journal of Hydrogen Energy, 41(45), pp. 20974-20986, 2016.

https://doi.org/10.1016/j.ijhydene.2016.05.096

[21] Mebarki, N., Rekioua, T., Mokrani, Z., Rekioua D. "Supervisor control for stand-alone photovoltaic/hydrogen/battery bank system to supply energy to an electric vehicle", International Journal of Hydrogen Energy, 40(39), pp. 13777-13788, 2015.

https://doi.org/10.1016/j.ijhydene.2015.03.024

[22] Mokrani, Z., Rekioua, D., Mebarki, N., Rekioua T., Bacha, S. "Energy management of battery-PEM Fuel cells Hybrid energy storage system for electric vehicle", In: 2016 International Renewable and Sustainable Energy Conference, (IRSEC), Marrakesh, Morocco, 2016, pp. 985-990. https://doi.org/10.1109/IRSEC.2016.7984073 
[23] Mebarki, N., Rekioua, T., Mokrani, Z., Rekioua, D., Bacha, S. "PEM fuel cell/ battery storage system supplying electric vehicle", International Journal of Hydrogen Energy, 41(45), pp. 2099321005, 2016.

https://doi.org/10.1016/j.ijhydene.2016.05.208

[24] Rekioua, T., Rekioua, D. "Direct torque control strategy of permanent magnet synchronous machines", In: 2003 IEEE Bologna Power Tech-Conference Proceedings, Bologna, Italy, 2003, Article number: 6 .

https://doi.org/10.1109/PTC.2003.1304660

[25] Rekioua, D., Rekioua, T. "DSP-controlled direct torque control of induction machines based on modulated hysteresis control", In: 2009 International Conference on Microelectronics, (ICM), Marrakesh, Morocco, 2009, pp. 378-381.

https://doi.org//10.1109/ICM.2009.5418603

[26] Aissou, R., Rekioua, T., Rekioua, D., Tounzi, A. "Robust nonlinear predictive control of permanent magnet synchronous generator turbine using Dspace hardware", International Journal of Hydrogen Energy, 41(45), pp. 21047-21056, 2016.

https://doi.org/10.1016/j.ijhydene.2016.06.109
[27] Cao, M., Li, S., Li, J., Wu, Y., Sun, H. "A Model-Compensation ADRC Strategy of Wind Energy Conversion System with DirectDriven PMSG", In: 37th Chinese Control Conference, (CCC), Wuhan, China, 2018, pp. 7520-7525. https://doi.org//10.23919/ChiCC.2018.8484111

[28] Ohiero, P. O., Cossar, C., Melone, J., Schofield, N. "A fast simulation model for permanent magnet synchronous motor (PMSM) based system", In: 7th IET International Conference on Power Electronics, Machines and Drives (PEMD 2014), 2014, pp. 1-6. https://doi.org//10.1049/cp.2014.0312

[29] Eghtedarpour, N., Farjah, E. "Distributed charge/discharge control of energy storages in a renewable-energy-based DC micro-grid", IET Renewable Power Generation, 8(1), pp. 45-57, 2014. https://doi.org/10.1049/iet-rpg.2012.0112

[30] Psarros, G. N., Papathanassiou, S. A. "Evaluation of battery-renewable hybrid stations in small-isolated systems", IET Renewable Power Generation, 14(1), pp. 39-51, 2020. https://doi.org/10.1049/iet-rpg.2019.0212 